\title{
Myotonic dystrophy type 1
}

\author{
Cam-Tu Emilie Nguyen MD, Craig Campbell MD MSc
}

\section{Myotonic dystrophy type 1 is a com- mon form of muscular dystrophy}

The prevalence of myotonic dystrophy type 1 ranges between 0.5 and 18.1 per 100000 population, making it the most common muscular dystrophy, ahead of Duchenne and fácioscapulohumeral muscular dystrophies. ${ }^{1}$ Myotonic dystrophy type 1 is especially prevalent in certain regions of Quebec. ${ }^{2}$ It is an autosomal dominant nucleotide repeat disorder. The mutant messenger RNA with expanded repeats has a toxic gain of function, resulting in widespread splicing dysregulation.

\section{Myotonic dystrophy type 1 shows} genetic anticipation

Genetic anticipation, the earlier and more severe presentation in offspring, relates to the unstable trinucleotide repeat mutation expanding in subsequent generations. Congenital myotonic dystrophy type 1 is the most severe manifestation of this disorder. Congenitally affected neonates with this manifestation are weak and hypotonic, and often require ventilation and feeding support. Mortality is about $25 \%$ in the first year. ${ }^{4}$ Strength and ability to feed and breathe improve in those who live beyond the first year.

CMAJ invites submissions to "Five things to know about ..." Submit manuscripts online at http://mc.manuscriptcentral. $\mathrm{com} / \mathrm{cmaj}$

\section{Myotonic dystrophy type 1 is multisystemic}

Myotonic dystrophy type 1 can present at any age but is typically diagnosed in adults. Although this disorder can present in many different ways (Appendix 1, available at www.cmaj.ca/lookup/suppl/doi:10.1503/cmaj.151384//DC1), facial and distal muscle weakness, along with grip myotonia, are key findings on examination. Given the risk of sudden death (described below), dominant inheritance and high penetrance, ${ }^{3}$ first-degree relatives and women of childbearing age who are at risk of carrying an affected child should be referred for genetic counselling.

\section{Cardiac arrythmia is a frequent cause of death}

Unlike other dystrophies, arrhythmias and other conduction abnormalities are the primary cardiac manifestation in myotonic dystrophy type 1 and require regular electrocardiographic (ECG) monitoring and referral to cardiology. ${ }^{5}$ Sudden cardiac death may be predicted by severe abnormalities detected through ECG monitoring and a diagnosis of symptomatic atrial tachyarrhythmias. ${ }^{5}$

\section{References}

1. Theadom A, Rodrigues M, Roxburgh R, et al. Prevalence of muscular dystrophies: a systematic literature review. Neuroepidemiology 2014;43:259-68.

2. Yotova V, Labuda D, Zietkiewicz E, et al. Anatomy of a founder effect: myotonic dystrophy in Northeastern Quebec. Hum Genet 2005;117:177-87.

3. Turner C, Hilton-Jones D. Myotonic dystrophy: diagnosis, management and new therapies. Curr Opin Neurol 2014;27:599-606.

4. Campbell C, Sherlock R, Jacob P, et al. Congenital myotonic dystrophy: assisted ventilation duration and outcome. Pediatrics 2004;113:811-6.

5. Groh WJ, Groh MR, Saha C, et al. Electrocardiographic abnormalities and sudden death in myotonic dystrophy type 1. N Engl J Med 2008;358:2688-97.

6. Logigian EL, Martens WB, Moxley RT, et al. Mexiletine is an effective antimyotonia treatment in myotonic dystrophy type 1. Neurology 2010;74:1441-8.

7. Puymirat J, Bouchard J-P, Mathieu J. Efficacy and tolerability of a $20-\mathrm{mg}$ dose of methylphenidate for the treatment of daytime sleepiness in adult patients with myotonic dystrophy type 1: a 2-center, randomized, double-blind, placebo-controlled, 3-week crossover trial. Clin Ther 2012;34:1103-11.

\section{Treatments are symptomatic}

No treatment to modify disease currently exists. However, mexiletine is effective in reducing myotonia based on evidence from randomized controlled trials (RCTs). ${ }^{6}$ In a small RCT, methylphenidate was found to decrease excessive somnolence seen in this disorder. ${ }^{7}$ There are some promising disease-modifying therapies entering clinical trials.
Competing interests: Craig Campbell has received a grant from Valerion Therapeutics and is a site investigator for Ionis Pharmaceuticals. Cam-Tu Emilie Nguyen is a site sub-investigator for Ionis Pharmaceuticals.

This article has been peer reviewed.

Affiliations: Department of Paediatrics (Nguyen), London Health Sciences Centre; Paediatric Neurology Clinic (Campbell), Children's Hospital, London Health Sciences Centre; Department of Epidemiology and Clinical Neurological Sciences, Western University, London, Ont.

Acknowledgements: Shannon Venance and Cynthia Gagnon provided valuable feedback on this manuscript.

Correspondence to: Craig Campbell, craig.campbell@lhsc.on.ca

CMAJ 2016. DOI:10.1503/cmaj.151384 